\title{
A retrofit strategy to achieve "Fast, Flexible, Future (F3)" pharmaceutical production processes
}

Singh, Ravendra; Rozada-Sanchez, Raquel; Wrate, Tim; Muller, Frans; Gernaey, Krist; Gani, Rafiqul; Woodley, John

Publication date:

2011

Document Version

Publisher's PDF, also known as Version of record

Link back to DTU Orbit

Citation (APA):

Singh, R., Rozada-Sanchez, R., Wrate, T., Muller, F., Gernaey, K., Gani, R., \& Woodley, J. (2011). A retrofit strategy to achieve "Fast, Flexible, Future (F3)" pharmaceutical production processes. Poster session presented at 21st European Symposium on Computer Aided Process Engineering, Chalkidiki, Greece.

\section{General rights}

Copyright and moral rights for the publications made accessible in the public portal are retained by the authors and/or other copyright owners and it is a condition of accessing publications that users recognise and abide by the legal requirements associated with these rights.

- Users may download and print one copy of any publication from the public portal for the purpose of private study or research.

- You may not further distribute the material or use it for any profit-making activity or commercial gain

- You may freely distribute the URL identifying the publication in the public portal 


\section{DTU A retrofit strategy to achieve "Fast, Flexible, Future $\left(F^{3}\right)$ " pharmaceutical production processes}

Ravendra Singh, ${ }^{a}$ Raquel Rozada-Sanchez, ${ }^{b}$ Tim Wrate, ${ }^{b}$ Frans Muller, ${ }^{b}$ Krist V. Gernaey, ${ }^{a}$ Rafiqul Gani, ${ }^{a}$ John M. Woodley ${ }^{a}$

${ }^{a}$ Department of Chemical and Biochemical Engineering, Technical University of Denmark, DK-2800 Lyngby, Denmark

${ }^{b}$ AstraZeneca Limited, Charter Way, Silk Road Business Park, Macclesfield, Cheshire SK10 2NA, UK

Introduction: A "Substrates Adoption Methodology (SAM)" and a generic nitro reduction process-plant template for a series of substrates with similar molecular functionality has been developed. The main idea is to combine the flexibility of batch processes with the efficiency of continuous processes.

\section{SAM identifies changes to a process-plant template:}

* Reagents (e.g. reducing agent, solvent, catalyst)

* Process equipment configuration

* Process operational conditions (e.g. T, P, F)

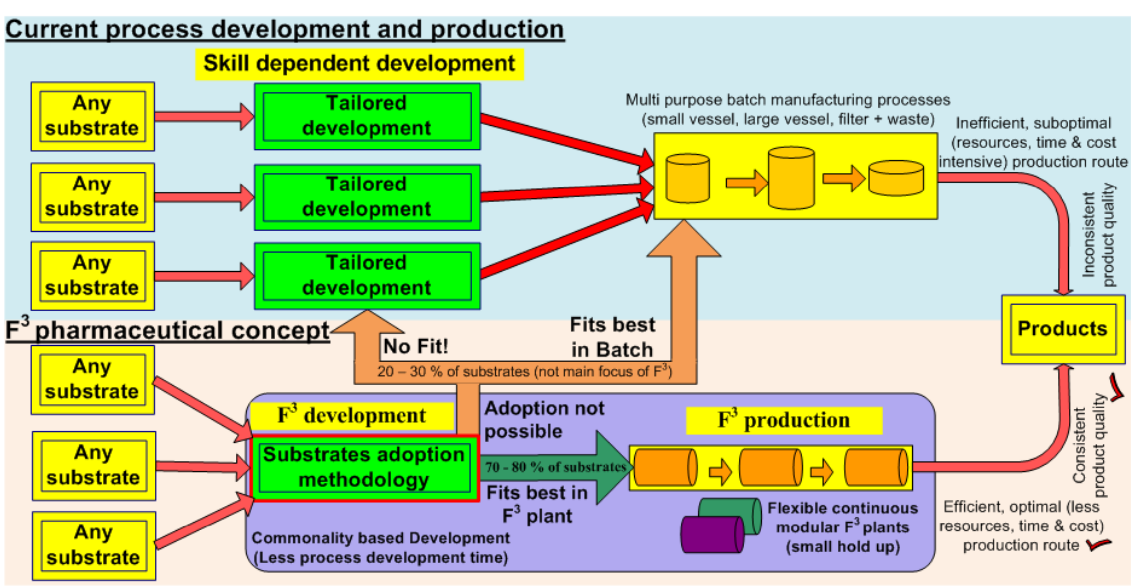

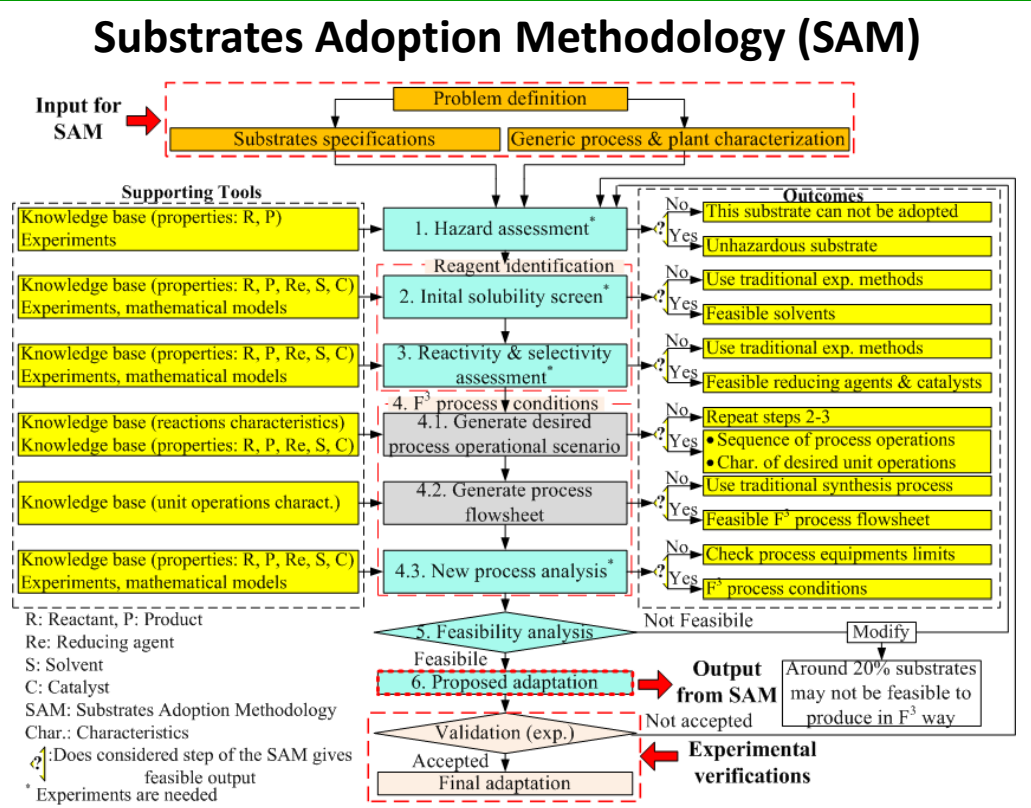

\section{Nitro reduction case study}

Amines are used in many pharmaceutical products and therefore make a good target for a generic process.

Problem definition: Adapt a generic nitro reduction process-plant template for the adoption of 2-Nitro-4'-chlorodiphenylamine

Generic case:

${\mathrm{R}-\mathrm{NO}_{2}+}_{\text {agent }}+\underset{\text { Solvent }}{\stackrel{\text { Catalyst }}{\longrightarrow}} \mathrm{R}-\mathrm{NH}_{2}+$ By-product Specific case:

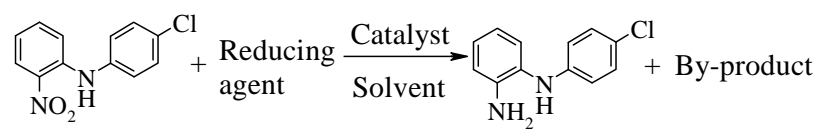

Generic nitro reduction process-plant template: Proposed adaptation (one alternative)

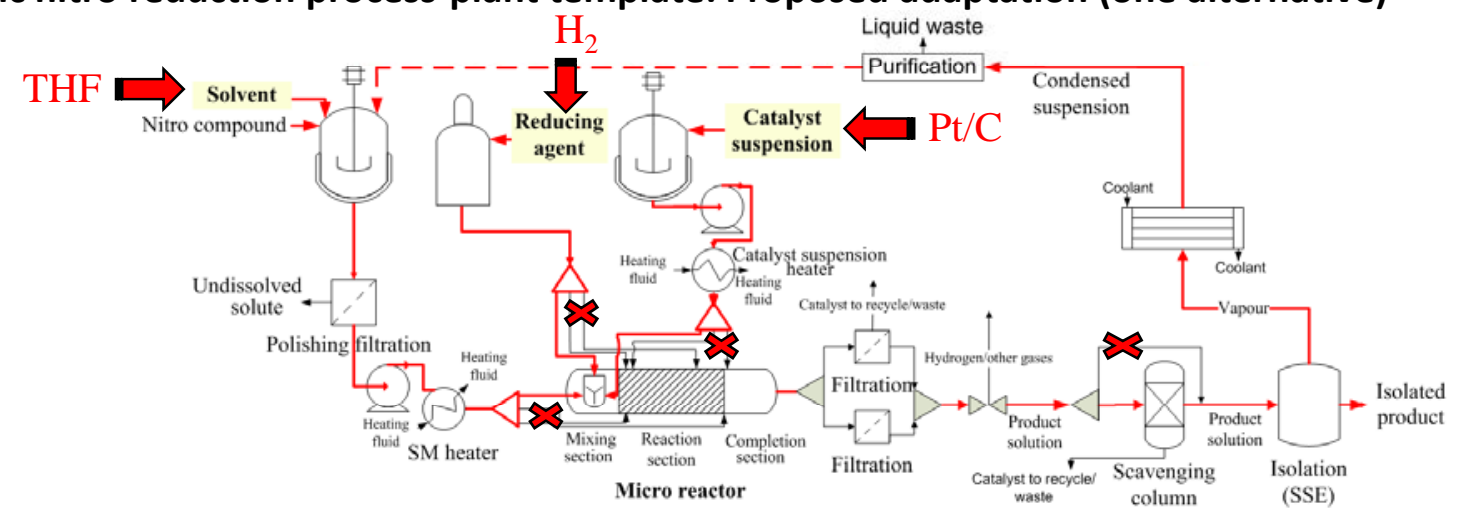

Conclusions: A generic nitro reduction Process-Plant template and Substrates Adoption Methodology (SAM) including the supporting tools (knowledge base, model library, graphical tool (operational window), solubility prediction and solvent selection tool) has been developed to achieve a flexible and fast production process. Acknowledgement: This work is funded by European Community's $7^{\text {th }}$ Framework Program under grant agreement $n^{\circ}$ 228867, $\mathrm{F}^{3}$ Factory. 